\title{
TINGKAT EFEKTIVITAS SISTEM INFORMASI REMOTE TRADING MENGGUNAKAN METODE UTAUT PADA PT CIPTADANA SECURITIES
}

\author{
Maria Gabby Winata \\ Sistem Informasi, Universitas Bina Nusantara, Jakarta Indonesia \\ E-mail : gabby.winata@gmail.com
}

Submission date: $2020-02-27$

Accepted date: $2020-03-25$

\begin{abstract}
Along with the rapid development of information technology, the Indonesian Stock Exchange (IDX) began to develop a more efficient transaction concept by starting to apply the concept of floorless trading. Which previously all places and processes of buying and selling shares were only centered on the IDX floor or better known as floor trading. The floorless trading system is a new stock trading transaction system implemented by the IDX by moving the place and process of buying and selling of shares to each securities company from what was previously centralized on the stock exchange (IDX). So now the concept of a new stock sale and purchase transaction, or better known as remote trading, has begun to be developed. The purpose of writing this research is to evaluate the remote trading system implemented by the company and provide input to improve the effectiveness of the remote trading system. This study uses the UTAUT methodology to evaluate and measure user acceptance, the results of which will be a reference to provide input to the company. The results achieved are a new system design created to meet user needs based on the analysis that has been done. With this new system design will increase system effectiveness and employee performance.
\end{abstract}

Keywords: Remote Trading, UTAUT, User Acceptance, System Design, Effectiveness.

\begin{abstract}
ABSTRAK
Seiring dengan pesatnya perkembangan teknologi informasi maka Bursa Efek Indonesia (BEI) mulai mengembangkan konsep transaksi yang lebih efisien yakni dengan mulai menerapkan konsep floorless trading. Yang mana sebelumnya seluruh tempat dan proses terjadinya transaksi jual beli saham hanya terpusat di lantai BEI atau lebih dikenal dengan istilah floor trading. Sistem floorless trading merupakan sebuah sistem transaksi jual beli saham baru yang diterapkan oleh BEI dengan memindahkan tempat dan proses terjadinya transaksi jual beli saham ke masing-masing perusahaan efek dari yang tadinya terpusat di lantai bursa (BEI). Maka sekarang ini mulai dikembangkan konsep transaksi jual beli saham yang baru atau lebih dikenal dengan istilah remote trading. Tujuan dari penulisan penelitian ini adalah mengevaluasi system remote trading yang diimplementasikan oleh perusahaan serta memberikan masukan untuk meningkatkan efektivitas system remote trading. Penelitian ini mengunakan metodologi UTAUT untuk melakukan evaluasi dan pengukuran terhadap user acceptance yang hasilnya akan menjadi acuan untuk memberikan masukan kepada perusahaan. Hasil yang dicapai adalah sebuah rancangan sistem baru yang dibuat untuk memenuhi kebutuhan user berdasarkan analisa yang telah dilakukan. Dengan rancangan sistem yang baru ini akan meningkatkan efektivitas sistem dan kinerja karyawan.
\end{abstract}

Kata Kunci : Remote Trading, UTAUT, User Acceptance, Rancangan Sistem, Efektivitas.

\section{PENDAHULUAN}

PT Ciptadana Securities merupakan sebuah perusahaan yang bergerak di dalam bidang sekuritas / pasar modal dan menjadi sebuah perusahaan perantara perdagangan saham di Bursa Efek Indonesia. Saat ini, PT Ciptadana Securities merupakan salah satu perusahaan sekuritas terbaik di Indonesia dengan perkembangan dan pertumbuhan daripada jumlah klien-klien yang mereka punya. Dengan visinya yakni Menjadi Financial Partner terbaik yang memberikan layanan, informasi dan solusi tepat bagi customer. Seiring dengan pesatnya perkembangan teknologi informasi maka Bursa Efek Indonesia (BEI) mulai mengembangkan konsep transaksi yang lebih efisien yakni dengan mulai menerapkan konsep floorless trading. Yang mana sebelumnya seluruh tempat dan proses terjadinya transaksi jual beli saham hanya 
terpusat di lantai BEI atau lebih dikenal dengan istilah floor trading.

Sistem floorless trading merupakan sebuah sistem transaksi jual beli saham baru yang diterapkan oleh BEI dengan memindahkan tempat dan proses terjadinya transaksi jual beli saham ke masing-masing perusahaan efek dari yang tadinya terpusat di lantai bursa (BEI). Maka sekarang ini mulai dikembangkan konsep transaksi jual beli saham yang baru atau lebih dikenal dengan istilah remote trading. Sistem remote trading ini sendiri memungkinkan para trader melakukan transaksi jual beli saham langsung ke bursa hanya dengan melalui sistem remote trading yang terkoneksi melalui jaringan internet khusus antara BEI dan perusahaan perantara efek yang melakukan transaksi. Dari diterapkannya regulasi floorless trading ini maka PT Ciptadana Securities mengembangkan sebuah sistem informasi remote trading.

Sistem ini dikembangkan secara in-house oleh departemen IT yang ada di PT Ciptadana Securities sendiri. Sistem ini diimplementasikan ke seluruh cabang PT Ciptadana Securities sejak April 2010 sehingga sampai saat ini seluruh proses transaksi jual beli saham di PT Ciptadana Securities sudah sepenuhnya menggunakan sistem remote trading. Seperti halnya sebuah sistem yang baru diimplementasikan di suatu organisasi maka sistem remote trading inipun harus dilakukan sebuah evaluasi untuk ditelusuri lebih lanjut seberapa efektif sistem remote trading ini dalam membantu proses bisnis yang terjadi di PT Ciptadana Securities . Model UTAUT (Unified Theory of Acceptance and Use of Technology) merupakan salah satu model penerimaan teknologi yang dikembangkan oleh Venkatesh, Morris dan beberapa peneliti lain. Model UTAUT ini sebenarnya merupakan sintesis atau penggabungan daripada elemen-elemen yang terdapat dalam 8 model penerimaan teknologi terkemuka lainnya dengan tujuan untuk memperoleh kesatuan pandangan mengenai user atau pengguna dari sebuah teknologi (Venkatesh et al., 2003).

\section{METODOLOGI PENELITIAN}

Metodologi yang digunakan dalam penelitian ini adalah sebagai berikut (Widiarsana, 2011) :

\section{Studi Pustaka}

Penulis dalam hal ini membandingkan beberapa metode penelitian berasal dari berbagai literatur / buku teks / jurnal sebagai pedoman.

\section{Studi Lapangan}

Metode yang digunakan dalam studi lapangan terdiri atas 3 (tiga) cara, yaitu (Sani, 2018):

a. Wawancara

Wawancara dilakukan kepada seluruh staff pengguna remote trading PT Ciptadana Securities, Direktur serta Kepala Divisi IT PT. Ciptadana Securities.

b. Penyebaran Kuesioner

Selain itu penulis juga menyebarkan kuesioner kepada seluru pengguna remote trading dan kemudian hasil kuesioner dan kemudian digambarkan menggunakan metode IPA Analysis yang mengukur hubungan antara persepsi konsumen dan prioritas peningkatan kualitas produk/jasa yang dikenal pula dengan quadrant analysis.

c. Dokumentasi

Merupakan metode pengumpulan dengan mengumpulkan dokumen-dokumen perusahaan yang diperlukan seperti dokumen-dokumen SDLC, User Requirement dan sebagainya.

d. Observasi

Observasi dilakukan di kantor PT. Ciptadana Securities di Jl. Sudirman kav 57-58, Jakarta, secara langsung.

\section{Metode Analisis dan Perancangan}

Metode analisa yang digunakan penulis untuk mengukur tingkat efektifitas sistem remote trading adalah menggunakan Metode UTAUT (Unified Theory of Acceptance and Use of Technology) dan kemudian akan digunakan untuk merancang desain interface serta fungsi-fungsi remote trading baru yang berguna untuk memenuhi ketidakpuasan user terhadap sistem yang berjalan. Penelitian ini termasuk data penelitian terapan (Applied Research) yang digunakan untuk memperbaiki praktek-praktek yang ada sekaligus untuk meningkatkan efektifitas sistem. Dalam penelitian ini digunakan 2 metode analisa statistik untuk menunjang penelitian ini, yaitu (Ardhi \& Endahuluan, 2016).

\section{a. Uji Regresi Linier}

Analisis regresi adalah studi mengenai ketergantungan variabel dependen dengan satu atau lebih variabel independen dengan tujuan untuk mengestimasi dan atau memprediksi nilai variabel dependen berdasarkan nilai variabel independen yang diketahui. Hasil analisis regresi adalah berupa koefisien untuk masing-masing variabel independen (Gujarati, 2008).

\section{b. Uji Autokorelasi}

Uji autokorelasi untuk mengetahui apakah dalam sebuah model regresi linier terdapat hubungan yang kuat baik yang positif atau negatif antar data yang 
ada dalam variabel-variabel penelitian. Untuk menentukan terjadi autokorelasi dapat ditentukan dengan Breusch-Godfrey Test. Pengujian ini dilakukan dengan menentukan nilai $\log$ dari nilai residual dari variabel independen dan dependennya (diberi nama residu 2), kemudian meregresikan nilai residual yang telah dilog-kan sebagai variabel independen bersama variabel independen lainnnya. Secara umum dasar pengambilan keputusannya adalah. (Sugiyono, 2006) :

1) Jika $t$-sig dari residu $2<\alpha(0.05) \rightarrow$ terjadi autokorelasi.

2) Jika $t$-sig dari residu $2>\alpha(0.05) \rightarrow$ tidak terjadi autokorelasi.

\section{HASIL DAN PEMBAHASAN}

Pengimplementasian system remote trading dalam sebuah perusahaan sekuritas seperti PT. Ciptadana Securities ini menunjang aspek efektifitas dan kinerja karyawannya, terutama di bidang trading saham secara online.

Adapun hal-hal yang akan dinilai sebagai keberhasilan dan peningkatan efektifitas daripada sistem remote trading ini. Dengan adanya penggunaan sistem remote trading dalam perusahaan, maka diharapkan adanya peningkatan performa dan kinerja para pegawai. Sehingga diduga adanya hubungan antara Performance Expectancy (X1) dengan Behavioral Intention (Y). Sementara itu interaksi yang baik antara user dan system juga saling menunjang, terlebih kemudahan sistem digunakan oleh user, pemahaman user akan pengoperasionalan sistem dari sini diduga adanya hubungan antara Effort Expectancy (X2) dengan Behavioral Intention (Y). Dan tingkat pengaruh lingkungan sekitar user dalam hubungannya faktor yang mempengaruhi penggunaan sistem remote trading, kenyamanan user dalam menggunakan sistem ini dari lingkungan di luar dirinya sendiri akan menciptakan suatu dugaan hubungan antara Social Influence (X3) dengan Behavioral Intention (Y).

Selain daripada itu semua pengaruh kebiasaan user menggunakan sistem pada keseharian pekerjaan mereka akan mempengaruhi perilaku mereka sehari-hari dalam menggunakan sistem remote trading ini, sehingga diduga adanya hubungan antara Behavioral Intention (Y) dan Use Behavior (Z).

Sementara itu faktor sumber daya dan keahlian-keahlian serta pemahaman user akan mempengaruhi mereka dalam penggunaan system remote trading, sehingga diduga adanya hubungan antara Facilitating Condition (X4) dan Use Behavior (Z).
Berikut ini adalah model penelitian yang terdiri dari variabel laten dan variabel operasional yang akan digunakan untuk mempermudah penilaian kepuasan user terhadap system yang digunakan, dalam hal ini adalah penggunaan system remote trading :

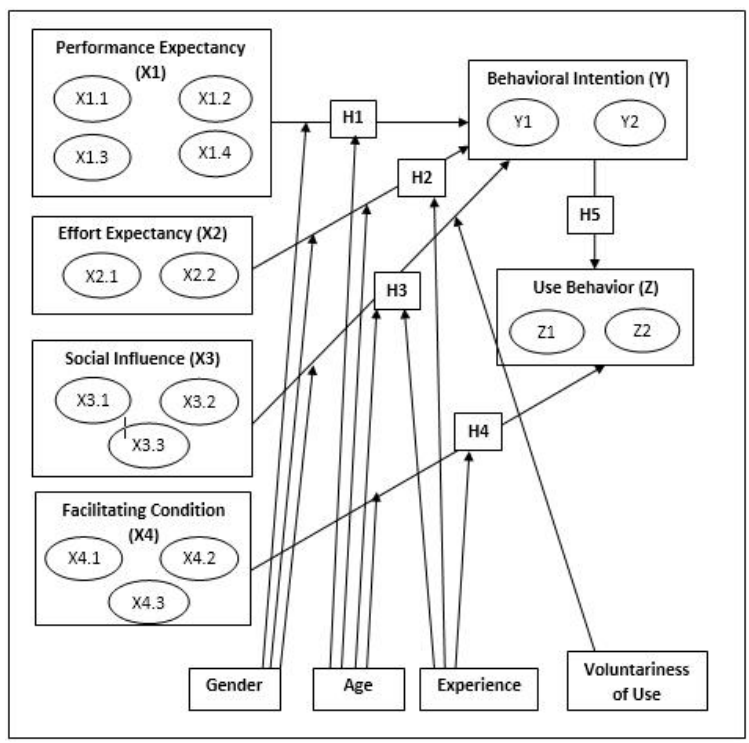

Sumber : (Winata, 2019)

Gambar : System Remote Trading

Keterangan :

\section{$\mathrm{X1}=$ Performance expectancy}

$\mathrm{X} 1.1$ = Tingkat kegunaan sistem

$\mathrm{X} 1.2$ = Percepatan waktu bekerja

$\mathrm{X} 1.3$ = Peningkatan produktifitas

$\mathrm{X} 1.4$ = Peningkatan kesempatan

$\mathrm{X} 2$ = Effort expectancy

$\mathrm{X} 2.1$ = Kemudahan pemahaman

$\mathrm{X} 2.2$ = Kemudahan pemakaian sistem

X3 = Social influence

X3.1 = Pengaruh lingkungan sekitar dalam pemakaian sistem

X3.2 = Kemampuan sistem membantu manajerial perusahaan

X3.3 = Kemampuan sistem membantu seluruh perusahaan

\section{X4 = Facilitating condition}

$\mathrm{X} 4.1$ = Sumberdaya yang diperlukan dalam sistem

$\mathrm{X} 4.2$ = Knowledge yang diperlukan dalam sistem

$\mathrm{X} 4.3$ = Kemudahan adanya helpdesk dalam sistem

$\mathrm{Y}=$ Behavioral intention

$\mathrm{Y} 1$ = Penggunaan sistem dalam (n) bulan kedepan

Y2 = Prediksi penggunaan sistem dalam (n)

bulan kedepan 
$\mathrm{Z}=$ Use Behavior

$\mathrm{Z1}=$ Tingkat kepercayaan diri user

$\mathrm{Z} 2$ = Tingkat keraguan user terhadap sistem

Hypothesis 1

H0 : Ada hubungan yang positif antara Performance Expectancy dengan Behavioral Intentions dalam penggunaan sistem remote trading yang dipengaruhi oleh Age dan Gender.

H1 : Tidak ada hubungan yang positif antara Performance Expectancy dengan Behavioral Intentions dalam penggunaan sistem remote trading yang dipengaruhi oleh Age dan Gender.

\section{Hypothesis 2}

H0 : Ada hubungan yang positif antara Effort Expectancy dengan Behavioral Intentions dalam penggunaan sistem remote trading yang dipengaruhi oleh Age, Gender, dan Experience.

H1 : Tidak ada hubungan yang positif antara Effort Expectancy dengan Behavioral Intentions dalam penggunaan sistem remote trading yang dipengaruhi oleh Age, Gender, dan Experience.

\section{Hypothesis 3}

H0 : Ada hubungan yang positif antara Social Influence dengan Behavioral Intentions dalam penggunaan sistem remote trading yang dipengaruhi oleh Age, Gender, Experience, dan Voluntariness of Use.

H1 : Tidak ada hubungan yang positif antara Social Influence dengan Behavioral Intentions dalam penggunaan sistem remote trading yang dipengaruhi oleh Age, Gender, Experience, dan Voluntariness of Use.

\section{Hypothesis 4}

H0 : Ada hubungan yang positif antara Facilitating Conditions dengan Use Behavior dalam penggunaan sistem remote trading yang dipengaruhi oleh Age dan Experience.

H1 : Tidak ada hubungan yang positif antara Facilitating Conditions dengan Use Behavior dalam penggunaan sistem remote trading yang dipengaruhi oleh Age dan Experience.

\section{Hypothesis 5}

H0 : Ada hubungan yang positif antara Behavioral Intentions dengan Use Behavior dalam penggunaan sistem remote trading.

H1 : Tidak ada hubungan yang positif antara Behavioral Intentions dengan Use Behavior dalam penggunaan sistem remote trading.

\section{Hypothesis 6}

H0 : Ada pengaruh antara Performance Expectancy dengan Behavioral Intentions dalam penggunaan sistem remote trading yang dipengaruhi oleh Age dan Gender.

H1 : Tidak ada pengaruh antara Performance Expectancy dengan Behavioral Intentions dalam penggunaan sistem remote trading yang dipengaruhi oleh Age dan Gender.

\section{Hypothesis 7}

H0 : Ada pengaruh antara Effort Expectancy dengan Behavioral Intentions dalam penggunaan sistem remote trading yang dipengaruhi oleh Age, Gender, dan Experience.

$\mathrm{H} 1$ : Tidak ada pengaruh antara Effort Expectancy dengan Behavioral Intentions dalam penggunaan sistem remote trading yang dipengaruhi oleh Age, Gender, dan Experience.

\section{Hypothesis 8}

H0 : Ada pengaruh antara Social Influence dengan Behavioral Intentions dalam penggunaan sistem remote trading yang dipengaruhi oleh Age, Gender, Experience, dan Voluntariness of Use.

$\mathrm{H} 1$ : Tidak ada pengaruh antara Social Influence dengan Behavioral Intentions dalam penggunaan sistem remote trading yang dipengaruhi oleh Age, Gender, Experience, dan Voluntariness of Use.

\section{Hypothesis 9}

H0 : Ada pengaruh antara Facilitating Conditions dengan Use Behavior dalam penggunaan sistem remote trading yang dipengaruhi oleh Age dan Experience.

H1 : Tidak ada pengaruh antara Facilitating Conditions dengan Use Behavior dalam penggunaan sistem remote trading yang dipengaruhi oleh Age dan Experience.

\section{Hypothesis 10}

H0 : Ada pengaruh antara Behavioral Intentions dengan Use Behavior dalam penggunaan sistem remote trading.

H1 : Tidak ada pengaruh antara Behavioral Intentions dengan Use Behavior dalam penggunaan sistem remote trading.

Untuk metode pengukuran data, digunakan 3 metode analisa yaitu :

\section{a. Populasi}

Populasi dalam penelitian ini adalah semua user daripada system remote trading yang ada di PT. Ciptadana. Sample dalam penelitian ini sebanyak 250 
orang yang merupakan karyawan dari PT. Ciptadana Securities.

\section{b. Teknik Sampling dan Jumlah Sample}

Teknik sampling dalam penelitian ini adalah non probabilistic sampling, yaitu metode judgment sampling, dimana tidak semua elemen populasi memiliki peluang / kesempatan sama untuk menjadi sampel. Dimana sampel yang akan diambil adalah para user yang langsung menggunakan system remote trading di PT. Ciptadana Securities yakni para sales yang berjumlah 125 orang.

\section{c. Penggunaan Skala Likert}

Skala pengukuran dalam jawaban kuesioner yang akan dipakai pada penelitian ini adalah skala Likert, dimana jawaban akan didefinisikan terlebih dahulu, sehingga dapat menghasilkan sebuah jawaban yang berkualitas dan berarti. Bentangan jawaban dalam skala Likert dalam penelitian ini diberi ukuran dari $1-6$, dimana setiap skala memiliki definisi sebagai berikut :

$$
\begin{aligned}
& \text { 1= Paling Tidak Penting / Sangat Tidak Puas } 2= \\
& \text { Tidak Penting } / \text { Tidak Puas } \\
& \text { 3= Netral } \\
& \text { 4= Cukup Penting / Cukup Puas } \\
& \text { 5= Penting / Puas } \\
& \text { 6= Paling Penting / Sangat Puas }
\end{aligned}
$$

Penggunaan skala ini ditujukan untuk mengevaluasi kinerja mana yang paling relevan di bawah keadaan tertentu dalam suatu perusahaan. Tujuannya untuk menguraikan secara efektif faktorfaktor yang penting bagi perusahaan.

Selain dari kuesioner, penelitian ini juga memperoleh data dari hasil pengamatan dan wawancara langsung dengan user. Data ini kemudian dijadikan sebagai data pendukung yang membuat penelitian ini menjadi lebih akurat. Sesuai dengan hasil yang diperoleh pada Tabel 4.50, didapati bahwa beberapa factor masih perlu improvement pada hal seperti:

- Sistem membuat pekerjaan yang dilakukan oleh user lebih simpel dan akurat.

- Memperbaiki tampilan sistem agar lebih user friendly.

- Menaikkan bandwidth agar lebih cepat diakses.

- Perlu adanya user awareness dan user guide untuk menggunakan system.

- Sistem remote trading harus align dengan sistem lain yang digunakan dalam perusahaan.

- Memperbaiki tampilan sistem agar lebih berorientasi pada keyboard dibandingkan dengan mouse.
Dari hasil penelitian, diperoleh informasi bahwa semua factor-faktor yang masih perlu diimprovisasi adalah bagian dari X1, X2, X3 dan X4 yang secara signifikan berpengaruh pada variable $\mathrm{Y}$ dan Z. Bila kita lihat kembali maka bisa dilihat bahwa sistem sudah diterima cukup baik, hal ini terwujud dengan adanya niat dan keinginan user untuk selalu menggunakan sistem dalam waktu beberapa bulan kedepan, serta sistem mampu mendukung keputusan yang diambil oleh manajerial.

Berdasarkan hal ini dan setelah penulis melakukan pengamatan dan wawancara langsung dengan user, maka dapat diperoleh perbandingan real antara keadaan setelah penggunaan sistem dengan keadaan sebelum adanya sistem diimplementasikan di perusahaan. Meskipun secara umum system remote trading sudah berjalan dengan baik memenuhi tujuan utamanya, namun berdasarkan hasil penelitian juga didapati adanya beberapa hal yang masih harus ditingkatkan dari system ini agar dapat berjalan lebih optimal. Pada bagian ini penulis menawarkan beberapa bentuk solusi yang mungkin dilakukan sebagai langkah perbaikan dan peningkatan untuk faktorfaktor yang harus segera ditingak lanjuti pada enhancement tahap II, karena pada enhancement tahap I tidak terdapat faktor-faktor yang perlu ditingkatkan lagi. Berdasarkan hasil kuesioner,

- Sistem membuat pekerjaan yang dilakukan oleh user lebih simpel dan akurat.

- Memperbaiki tampilan sistem agar lebih user friendly

- Menaikkan bandwidth agar lebih cepat diakses

- Perlu adanya user awareness dan user guide untuk menggunakan sistem

- Sistem remote trading harus align dengan sistem lain yang digunakan dalam perusahaan

- Memperbaiki tampilan sistem agar lebih berorientasi pada keyboard dibandingkan dengan mouse.

Dari keseluruhan faktor tersebut di atas, maka beberapa solusi yang ditawarkan diuraikan pada pointpoint di bawah ini.

\section{Solusi untuk Perbaikan Kinerja Sistem}

Berdasarkan pembahasan hasil pemetaan pada point variable performance expectancy (X1), diketahui adanya beberapa informasi yang menjadi request tambahan dari user, yang diharapkan dapat diprovide oleh sistem, guna mendapat hasil transaksi yang lebih simpel dan akurat. Beberapa masukan tambahan informasi tersebut diuraikan kembali sebagai berikut : 
1. Adanya informasi data histori transaksi client yang bisa diexport ke Excel / PDF.

2. Adanya informasi mengenai recap harga saham yang turun / naik pada setiap jam pembukaan dan penutupan market setiap harinya.

3. Adanya informasi mengenai recap client order power yang mendekati low level power pada setiap jam pembukaan dan penutupan market setiap harinya.

Dari ketiga request tersebut, kemudian dibentuk sejumlah rancangan layar sebagai bentuk solusi yang ditawarkan dan memungkinkan dapat dilakukan untuk memenuhi kebutuhan user. Beberapa racangan layar yang dibuat antara lain untuk informasi portofolio data histori transaksi client, recap client order power yang mendekati low level dan recap harga saham yang turun / naik.

\section{Solusi untuk Permasalahan Effort Expectancy, Facilitating Condition, Social Influence}

Berkaitan dengan permasalahan effort expectancy, beberapa halyang diduga penyebabnya, seperti yang sudah dirincikan antara lain adalah pengoperasionalan system yang mudah dipelajari. Hal ini sering terjadi ketika ada sales baru yang masuk ke Ciptadana dan ingin mulai bertransaksi menggunakan system. Biasanya yang terjadi adalah mereka sibuk bertanya satu sama lain, maka secara tidak langsung hal ini mengganggu konsentrasi sales lainnya. Solusi yang bisa ditawarkan adalah dengan menambahkan fungsi help dan FAQ di system remote trading yang berjalan. Karena selama ini untuk dokumentasi user manual belum disosialisasikan sedemikian rupa sehingga banyak sales yang merasa kesulitan untuk menggunakan system tersebut dan lebih banyak bertanya langsung ke teman satu departemen atau menghubungi departemen IT. Oleh karena itu dengan ditambahkannya fungsi help dan FAQ memungkinkan user untuk langsung mencari dan mempelajari system itu sendiri dari user manual dan informasi yang sudah disediakan. Tentunya user manual dan informasi yang disediakan pun haruslah relevan dan uptodate dengan system yang berjalan.

Lalu dengan masalah dengan Facilitating Condition, dimana masalahnya terletak di bagian tidak align-nya system yang lain dengan system remote trading. Semisalnya saja untuk fungsi mengeksport data-data yang ada di system remote trading ke dalam bentuk Excel atau CSV agar dapat dieksport ke sistem lain yang digunakan di dalam perusahaan belum disediakan di semua menu, sehingga user merasa kesulitan untuk mengolah data tersebut ke dalam system lainnya dan memilih untuk menginput data tersebut agar dapat diolah di system lainnya. Solusi yang bisa ditawarkan adalah untuk segera mengintegrasi data-data yang digunakan ke dalam sebuah file atau converter agar data dapat bisa langsung dimasukkan ke system lainnya agar dapat diolah tanpa harus menggunakan inputan manual seperti yang dilakukan sekarang ini untuk menghindari human error dan oversight.

Terakhir berikaitan dengan Social Influence, masalahnya terletak di ketidakawasan/ ketidaktelitian user dalam menggunakan sistem tersebut. Hal ini sering ditemui ketika user sedang melakukan proses jual-beli saham melalui system dan terjadi error, hal pertama yang dilakukan adalah menghubungi orang IT untuk melakukan komplen atas sistem tersebut. Ternyata kebanyakan penyebab dari peristiwa ini hanya karena ketidaktelitian dari user bahwa terkadang client order power milik client mereka tidak mencukupi lagi atau format input transaksi mereka salah. Solusi yang dapat ditawarkan adalah menggunakan alert / pop-up message untuk mengingatkan user apabila client order power mereka tidak mencukupi atau format inputan mereka salah sehingga order transaksi tidak dapat diinput ke system.

\section{KESIMPULAN}

Berdasarkan hasil penelitian yang dilakukan melalui penyebaran kuesioner didapati bahwa faktorfaktor performance expectancy, effort expectancy, social influence terbukti memiliki hubungan bahkan memberikan pengaruh yang signifikan terhadap Behavioral Intention To Use The System dan faktor-faktor Behavioral Intention To Use The System dan Facilitating Condition terbukti memiliki hubungan bahkan meberikan pengaruh yang signifikan terhadap Use of Behaviour. Dengan kata lain melihat hubungan dan pengaruh antar variabel - variabel di atas dan apabila kinerja daripada system ini dapat dimanfaatkan dengan optimal maka efektivitas daripada system remote trading ini dapat dikatakan sudah maksimal.

Namun di sisi lain, berdasarkan hasil penelitian kesesuaian antara kepentingan dengan kepuasan user terhadap system remote trading, didapati masih ada beberapa faktor dari system yang perlu segera ditingkatkan melalui enhancement tahap ke II agar kinerja dari system ini dapat menjadi lebih optimal. Faktor-faktor tersebut antara lain :

1. Pada Performance Expectancy, perlu diadakan perbaikan pada kinerja dan proses kerja system.

2. Pada Effort Expectancy, perlu diperbaiki pengoperasionalan system agar lebih mudah dipelajari.

3. Pada Social Influence, perlu ditingkatkan ketelitian dan keawasan user dalam menggunakan system remote trading.

4. Pada Facilitating Condition, perlu diintegrasikannya system remote trading dengan sistem-sistem lain yang dipakai di dalam perusahaan. 
Beberapa enhancement yang perlu dilakukan di atas, tidak serta merta membuat sistem ini dikatakan tidak efektif. Dengan berdasar pada fakta-fakta yang didapat di lapangan, maka disimpulkan bahwa seluruh tujuan utama dari manfaat awal yang ingin dicapai dari system ini adalah benar tercapai pada masa implementasi sistem ini. System remote trading terbukti telah menjadi solusi bisnis yang dapat meneydiakan analisa informasi yang relevan dan up to date, sehingga dapat mendukung berbagai pengambilan keputusan khusus bagi user di Brokerage dan Board of Directors.

\section{DAFTAR PUSTAKA}

Ardhi, R., \& Endahuluan, I. P. (2016). Komparasi Metode SAW dan TOPSIS untuk Menentukan Prioritas Perbaikan Jalan. Jurnal Teknik Elektro, $8(1), 8-11$.
Gujarati, D. N. (2008). Ekonometrika Dasar (T. S. Zain (ed.)). Erlangga.

Sani, A. (2018). Penerapan Metode K-Means Clustering Pada Perusahaan. Jurnal Ilmiah Teknologi Informasi, 353, 1-7.

Sugiyono. (2006). Metode Penelitian Kuantitatif Kualitatif dan $R \& D$. Alfabeta.

Venkatesh, V., Morris, M. G., Davis, G. B..Davis, F. D. (2003). User acceptance of Information Technolog Toward a Unified View. MIS Quarterly, 27(3), 425-478.

Widiarsana, I. G. . (2011). Metode Klasifikasi KNearest Neighbor (KNN). Fakultas Teknik, Universitas Udayana.

Winata, M. G. (2019). Tingkat Efektivitas Sistem Informasi Remote Trading Menggunakan Metode Utaut Pada Pt Ciptadana Securities. 
